\title{
Wikileaks: transparencia total. Límites y posibilidades de una demanda utópica ${ }^{1}$
}

\author{
Luis Pablo FrancescutTI \\ Universidad Rey Juan Carlos de Madrid \\ luispablo.francescutti@urjc.es
}

Recibido: 16/06/2011

Aceptado: 15/11/2011

\begin{abstract}
Resumen
El affaire Wikileaks ha puesto sobre la mesa la idea de transparencia social y política en sociedades complejas como las nuestras. No resulta fácil dilucidar los alcances de tal concepto. ¿Qué entraña exactamente esa clase de transparencia? ¿Cómo se mide el grado de opacidad de una sociedad? ¿Es realista pedir una transparencia completa al Estado y sus organismos? ¿Es posible abolir el secreto? ¿Hasta dónde se puede satisfacer esta demanda? ¿Suponen las filtraciones de Wikileaks un mojón en la marcha de la Humanidad hacia una mayor transparencia, como afirman sus partidarios? Tales son algunos interrogantes planteados por el fenómeno Wikileaks a los que este trabajo intenta aproximar una respuesta. Con ese propósito hemos reconstruido la andadura histórica del concepto de transparencia, para luego abordar su ubicación en el sistema de la comunicación masiva, seguido de un análisis crítico desde perspectivas sociológicas y semióticas, y de la propuesta de una noción practicable de transparencia informativa.
\end{abstract}

Palabras clave: Wikileaks, transparencia, secreto, semiótica

\section{Wikileaks: Total Transparency. Limits and Possibilities of a Utopian Demand}

\begin{abstract}
The Wikileaks story has put the idea of social and political transparency in complex societies like ours at center stage. However, it is not easy to elucidate the meaning of that concept. What does exactly such transparency entails? How can be measured the level of opacity in a given society? Is it reasonable to demand the State and its institutions full transparency? Is it possible to abolish secrecy? To what extent can these demands be fulfilled? Are Wikileaks' deeds a major step on the path to greater transparency, as its supporters claim? These are some of the many questions sparked by the Wikileaks affair. In order to answer them, this article argues for a more complex understanding of the concept of transparency. We begin with a reconstruction of its historical development, then we proceed to examine its place in the mass communication system, followed by a critical analysis from sociological and semiotical points of view and the proposal of a feasible notion of information transparency.
\end{abstract}

Keywords: Wikileaks, Transparency, Secret, Semiotics

Referencia normalizada: FRANCESCUTTI, Luis Pablo (2012): "Wikileaks: Transparencia total. Límites y posibilidades de una demanda utopica". Estudios sobre el mensaje periodístico. Vol. 18, núm. 1, págs.: 89-100. Madrid, Servicio de Publicaciones de la Universidad Complutense.

Sumario: 1. Introducción. 2. Recorrido de un concepto iluminista. 2.1. Transparencia y publicidad. 2.2. De la publicidad a la transparencia informativa. 3. La naturaleza del secreto. 4. Conclusiones: por una transparencia razonable. 5. Referencias bibliográficas

1 Este trabajo es resultado de las reflexiones realizadas en el marco del proyecto de $\mathrm{I}+\mathrm{D} E l$ fenómeno wikileaks en españa: un analisis semiotico y mediologico, dirigido por el catedrático Jorge Lozano Hernández (referencia CSO2011-23315). 


\section{Introducción}

Las filtraciones de datos confidenciales sobre la política exterior estadounidense que desde el año 2007 viene realizando la organización Wikileaks han colocado en el centro del debate mediático e intelectual cuestiones estratégicas como la posibilidad de la transparencia social y la vigencia del secreto en la contemporaneidad. Que figuras de la talla de Umberto Eco, Timothy Garton Ash, Daniel Dayan, Manuel Castells y Noam Chomsky, entre otros, hayan sentido la necesidad de intervenir en la polémica da una idea de la trascendencia que el asunto ha cobrado para las ciencias de la comunicación.

Antes de entrar en materia, conviene recordar que el concepto original de transparencia alude a una propiedad óptica de la materia, una cualidad de los cuerpos translúcidos: una categoría de la física que por un pase de manos metafórico se viene aplicando sobre todo al Estado, para dar cuenta del grado de conocimiento público que existe en una sociedad dada del funcionamiento de sus instituciones políticas. Correlativamente, su antónimo, la opacidad, funciona como otra metáfora, esta vez negativamente cargada: es el atributo de quienes tienen algo que ocultar, algo que sustraer a la mirada pública.

En este trabajo estudiaremos esa metáfora de transparencia junto con la quintaesencia de la opacidad, el secreto. Para ello comenzaremos haciendo una breve genealogía conceptual; a continuación analizaremos su declinación como transparencia informativa y la ambivalente relación que mantienen con esta los medios de comunicación, la estrecha conexión existente entre la transparencia y el secreto; por último, valoraremos los pros y los contras de las crecientes demandas de publicidad y concluiremos defendiendo una versión practicable de transparencia informativa.

\section{Recorrido de un concepto iluminista}

\subsection{Transparencia y publicidad}

Decíamos en el anterior epígrafe que transparencia y opacidad funcionan como metáforas de ciertos estados de la sociedad. ¿Cuándo entraron en circulación? La literatura coincide en señalar al siglo XVIII. Dicha centuria fue testigo del afán de Jean Jacques Rosseau por mostrarse como alguien "cristalino" (patente en el exhibicionismo desplegado en sus Confesiones) y de su afición por los pequeños Estados, en donde al ciudadano le resulta más fácil vigilar al poder y a los malos gobernantes les cuesta más ocultar sus fechorías; y fue testigo asimismo de la promoción por Kant y Constant del concepto emparentado de "publicidad", que Bentham utilizaría como sinónimo de transparencia: "In the darkness of secrecy, sinister interest and evil in every shape, have full swing.[...] Where there is no publicity there is no justice" (citado en BAUME, 2011). Ambos conceptos son enarbolados por los ilustrados en su rechazo de lo oscuro, las máscaras, el convencionalismo y las intrigas palaciegas. Ellos buscaban arrojar luz en las tinieblas del Poder (ADORNO y HORKHEIMER, 1969), y a ellos debemos la simbología iluminista que ha pervivido hasta hoy: luz, claridad, lucidez, oscurantismo, tenebroso.

El concepto de publicidad reenvía a la distinción público/privado, de gran raigambre en el pensamiento político occidental (THOMPSON, 1997:163 y ss.). Lo público es visible, mientras lo privado se halla sustraído a la vista de los demás (la mirada pú- 
blica). La publicidad deviene un ideal político del liberalismo democrático y de las restantes corrientes progresistas. La publicidad burguesa se concretiza en la existencia de la opinión pública y de espacios de debate físicos como los cuerpos representativos (parlamentos) y simbólicos como los habilitados por la prensa (HABERMAS, 2009).

En el plano visual, tiene su correlato en el régimen de visibilidad que se instaura en Occidente en el siglo XIX. Los historiadores de la fotografía (FreUND, 1993; SoNTAG, 1996) refieren cómo la fulgurante implantación y difusión de la técnica de reproducción de imágenes ideada por Daguerre empalmó con una "bulimia icónica" masiva, inducida por un anhelo democratizador de acceso a las imágenes ajenas y propias, bienes hasta entonces restringidos a la aristocracia y el clero, los únicos que podían hacerse retratar por pintores de cámara y coleccionar imágenes en sus pinacotecas privadas. A partir de aquí crecientemente se captarán lugares inaccesibles o escondidos por tabúes sociales.

Puede decirse que el ideal de transparencia social y política forma parte del dispositivo mental que trajeron consigo la Ilustración y las revoluciones burguesas ${ }^{2}$. Con todo, hay que matizar esta afirmación. Paolo FABBRI ha recordado la "dimensión críptica" de la Ilustración -y no solo crítica-, patente en la fascinación de los ilustrados por sociedades secretas como la masonería o por los códigos cifrados (cit. en FrancesCUTTI, 2007: 31). Por añadidura, la democracia burguesa introdujo nuevas opacidades. Un ejemplo: las ejecuciones y castigos que el Antiguo Régimen llevaba a cabo públicamente pasaron a esconderse tras las paredes de los penales decimonónicos; el espectáculo ejemplarizante cedió su lugar al dispositivo panóptico, en virtud del cual las personas quedaban expuestas a la mirada vigilante del poder (FOUCAULT, 2004), dispositivo del cual proceden los sistemas de vigilancia actuales (videovigilancia, escuchas telefónicas, satélites espías, etc.) gestionados por agencias secretas. Y el panóptico fue promovido precisamente por el gran adalid de la transparencia, Jeremy Bentham. Por no hablar de "secretos burgueses" como el secreto comercial o industrial, consustancial a la competencia por los mercados (encarnado en la misteriosa fórmula de la Coca Cola).

La contradicción entre esa vocación de transparencia y el secretismo del poder fue descrita por HABERMAS (2009: 90) como una tensión históricamente establecida entre la doctrina de la Razón de Estado forjada en el siglo XVI a ejemplo de los Arcana Imperii, de la cual se deriva y justifica el secreto de Estado, y el avance gradual de la legislación racional gestada en el debate público. En apariencias, la tensión se fue decantando a favor del último polo, con la consiguiente reducción del hermetismo estatal, que sin embargo nunca desapareció del todo ${ }^{3}$, como veremos más adelante.

2 Dicho ideal impregnó la arquitectura tan pronto como el acero y el vidrio hicieron viables las construcciones "transparentes", tan caras al Movimiento Moderno. Que mantiene su vigencia lo confirma la cúpula acristalada del Reichstag berlinés, construida en 1999: su sentido, indica el cartel allí colocado, es el de demostrar a los visitantes que el funcionamiento de la democracia alemana (la sala de Pleno del Parlamento federal situada justo debajo de la cúpula), se halla a la vista de todos.

3 Veamos un par de casos: la diplomacia secreta sufrió un golpe mortal en 1917, tras la publicación por los bolcheviques de los pactos ocultos por los cuales las potencias coloniales se 


\subsection{De la publicidad a la transparencia informativa}

En el marco de la publicidad burguesa irrumpe la prensa liberal de masas. Desde sus orígenes, ésta hizo de la exigencia de transparencia pública uno de sus caballos de batalla. A finales del siglo XIX, los periodistas y fotoperiodistas muckrakers consagraron como rutina profesional la tarea de "proyectar luz" sobre las oscuras trastiendas donde políticos y poder económico fraguan sus componendas (GALLAGHER, 2006), estableciendo como premisa del periodismo de investigación la convicción de que, a todo momento, en algún lugar, alguien conspira contra el bien común. Para los profesionales de la información, transparencia pasó a significar en primer lugar el acceso irrestricto de la prensa a las fuentes oficiales y los documentos públicos.

Aparte de los periodistas, esa exigencia ha sido asumida por otros sectores políticos y sociales. Un indiscutible punto de referencia en la materia lo representa la Ley de Libertad de Información de Estados Unidos (Freedom of Information Act/FOIA), que desde 1966 garantiza a sus ciudadanos el derecho de acceso a los archivos federales. Nacida de la frustración de algunos legisladores para obtener información del Estado federal, cuyo hermetismo se había acentuado bajo el influjo del macartismo (LEMOV, 2011), la ley ha inspirado en otros países más de 90 iniciativas tendentes a regular el acceso a la información pública (BERTONI, 2011). Que Wikileaks quiere situarse en su estela lo acredita la inserción en un lugar destacado de su sitio web (www.wikileaks.ch) de una cita extraída de la revista Time, en la que se dice de la organización: "Could become as important a journalistic tool as the Freedom of Information Act".

En paralelo eclosionó otro fenómeno relacionado con la demanda de transparencia informativa, en tándem con la prensa: la aparición y posterior consagración mediática y jurídica de la figura del Whistle blower (expresión traducible como "el que sopla el pito o el silbato"), esto es, una persona que denuncia públicamente la conducta errónea o ilegal de una institución, a la que por lo habitual pertenece (JOHNSON, 2002). Entre ellos destacan Daniel Ellsberg, el analista de Rand Corp. que en 1971 entregó a The New York Times los denominados "Papeles del Pentágono". Otro célebre Whistler blower es el técnico israelí Mordejai Vanunu, que en 1986 informó a The Sunday Times del arsenal nuclear secreto israelí. El soldado estadounidense Bradley Manning, que pasó a Wikileaks los cables de las embajadas de su país, es el último de esa serie.

Junto con las contribuciones del periodismo de investigación y de las leyes que consagran el "derecho del pueblo a saber", debemos mencionar el impacto de la televisión. En un texto ya clásico, MEYrovitz (1985) dio cuenta brillantemente del régimen de visibilidad por ella instituido. Él muestra cómo ese medio modificó drásticamente la distinción público/privado, retraducida por él en la terminología goffmaniana front stage/backstage (en inglés: delante del escenario/detrás del escenario). $\mathrm{Al}$ operar sus cámaras entre los bastidores de la gestión política, la "máquina revela-

repartían el Imperio Otomano. Pero su desaparición no aparejó el fin del secreto en las relaciones internacionales: las "operaciones encubiertas" dirigidas por los Ejecutivos estadounidenses en distintas partes del mundo a espaldas del Congreso hasta los años ' 80 proporcionan un dato elocuente. Véase WoODWARD, 1988. 
dora de secretos" (secret exposing machine) proyectó al primer plano el backstage de los acontecimientos; lo cual, además de desdibujar la frontera entre front stage y backstage y crear borrosas zonas intermedias, expuso al escrutinio de la audiencia esferas de la vida política y social que permanecían fuera del campo visual público (las intimidades de la Casa Blanca, los horrores de la guerra, las negociaciones políticas...).

A eso se añaden las posibilidades generadas por las nuevas tecnologías de la información (TIC), que van desde las filtraciones de datos por obra de los "piratas informáticos", hasta las posibilidades que en el terreno de la visual ofrecen portales como YouTube, que permiten exhibir la propia vida sexual secreta (pornografía amateur) o exponer el backstage de acontecimientos que no han sido captados por las cadenas televisivas o que éstas no han querido transmitir. En pocas palabras: las TIC "democratizan" las habilidades develatorias ejercidas casi en exclusividad por el sistema de medios en comandita con unos pocos whistleblowers estratégicamente situados.

Cabalgando en la cresta de esa ola tenemos a las demandas por la apertura de los archivos clasificados. Este requerimiento multiforme tiene detrás a toda clase de actores sociales: víctimas de la represión dictatorial, de los ensayos clínicos clandestinos, de la contaminación ambiental; actores que coinciden en reclamar la entrega de información vital que turbios intereses ocultan. Con esas exigencias la prensa mantiene una relación oscilante; ora ridiculiza la manía persecutoria de sus promotores (así ha procedido con quienes denuncian la existencia de documentos sobre OVNIs en archivos oficiales), ora las apoyan o directamente las orquestan (recuérdese la campaña contra la versión oficial de los atentados del 11 de Marzo de 2004 en Madrid, impulsada por medios madrileños). A propósito de esto último resulta oportuno agregar que las recientes teorías de la conspiración cuajaron al calor de la demanda de transparencia, a la cual parasitan y refuerzan; mas cuando se abren los archivos y no se verifica el secreto denunciado (como ocurre con los presuntas datos clasificados sobre platillos voladores), en lugar de asumir que no había tal, sus partidarios replican, lanzándose en una fuga infinita hacia otros secretos, que alguien destruyó las pruebas (FENSTER, 1999).

La dinámica inaugurada en la Ilustración en pos de una progresiva y creciente publicidad $^{4}$ del sistema político y de la vida social ha tenido entre sus agentes más activos a los medios de comunicación, excepción hecha de los períodos de autoritarismo en los que el sistema de medios sufre censura, o se autocensura por temor a represalias o por complicidad con el poder (la actitud de los periódicos tradicionales ante las

${ }^{4}$ Ese proceso se ha desenvuelto en íntima conexión con la consolidación de las democracias burguesas. De él se mantuvieron al margen los países socialistas, regidos por opacos sistemas de poder (siendo los más herméticos los círculos superiores de la estructura política, que en el caso soviético dieron lugar a la "kremlinología", un saber especializado en inferir a partir de escasísimos indicios el funcionamiento interno del Kremlin). La caída del comunismo y su sustitución por regímenes democráticos ha hecho que dichas naciones se sumen, con desigualdades, a la tendencia observada en Occidente. 
dictaduras apoyadas por las clases dominantes, de las cuales aquellos fungen de órganos de expresión). El ethos periodístico actual descansa en la presunción de que "gracias a la comunicación, el hombre es transparente a la sociedad y la sociedad es transparente para le hombre. Los medios modernos fundan su política de expansión sobre el tema: nada, en ninguna parte, debe jamás permanecer secreto" (BRETON, 1997:60).

El papel clave de los medios se ha visto reforzado con el acuerdo pactado entre cinco periódicos de referencia y Wikileaks. En plena revolución digital, las filtraciones de un whistleblower llegan una vez más al público a través de canales convencionales, cuyo tradicional rol de "gatekeepers" se fortalece pese a la competencia de la blogosfera $^{5}$ (resulta significativo que ese fortalecimiento se deba a la decisión de una organización liderada por un exhacker). En cualquier caso, conviene insistir en que a la prensa le importa sobre todo su acceso a la información, sea a través de los canales públicos o de los reservados. Un medio con una buena red de fuentes en los entresijos del poder puede sacar provecho de la opacidad oficial; "tener los papeles, tener una garganta profunda" es una gran baza en la lucha por el éxito profesional y la legitimidad. Los canales reservados son más ágiles que los engorrosos procedimientos que requiere hacer valer legalmente el derecho a la información ${ }^{6}$ (por otra parte, recurrir a ellos no impide publicar los documentos obtenidos por quienes han ejercido tal derecho).

En este sentido preciso, la prensa necesita del secreto para transgredirlo y beneficiarse de la difusión de "primicias" confidenciales. Lo dice un viejo adagio profesional: un buen periodista no vale tanto por las informaciones que tiene en su poder, sino por saber cuáles de ellas no se deben publicar. Como bien señala Umberto Eco, la fuerza del que asegura conocer un secreto no radica en ocultar algo sino en hacer creer que existe un secreto. Los medios, proclamándose en posesión de secretos vitales, magnifican su importancia de cara a la clase política, a los anunciantes y al público, aún cuando algunos de ellos a la postre demuestren ser secretos de Pulcinella, vale decir, irrisorios. Lo cual nos conduce a la última parada de nuestro itinerario: la naturaleza del secreto.

\section{La naturaleza del secreto}

Como ha ido quedando de manifiesto en las páginas anteriores, en la noción de transparencia juega un papel cardinal el secreto, al que se considera un residuo oscurantista -si bien uno fundamental- a eliminar. Adherida a esa creencia se halla la convicción de que todo secreto oculta información importante, y de allí la necesidad de hacerla pública. La certeza respecto de la importancia del secreto conecta con otro supuesto

5 Se vuelve a cumplir la vieja ley: la irrupción de un nuevo medio de comunicación -en este caso Internet- no suprime a los antecedentes, sino que da lugar a reacomodamientos y posteriores sinergias.

6 "Regarding how journalism has used these laws, a first point to highlight is that journalists use access to information laws less then expected. As we mentioned, the requests submitted by journalists represent between $5 \%$ and $16 \%$ of the total requests made to public institutions" (BERTONI, 2011). 
muy difundido en nuestros días: el de que toda información es importante ${ }^{7}$. De él participa plenamente la prensa, pues ésta, señala Jorge LozANO (1985), "considera que todo (noticia) interesa a la opinión pública, negando el secreto. Se olvida que para que haya secreto tiene que haber interés en el otro por conocer qué se oculta. Es excesivo creer que se sabe que el otro quiera saber". La certidumbre acerca de la "bulimia informativa" del público sirve de piedra angular del ethos periodístico: la prensa tiene que cumplir con su misión develadora porque el pueblo quiere saber.

La transparencia supone la disolución de los secretos, vale decir, la creencia en la factibilidad de una sociedad sin zonas de penumbra. Contra esa suposición se alzaba Georg Simmel (1906: 467-8) cuando sostenía que tal ente jamás podría existir; es más, contradiciendo la esperanza en la disminución progresiva de la opacidad social, afirmaba: "la convivencia humana en igualdad de las restantes circunstancias exige una misma cantidad de secreto, variando tan sólo los contenidos de éste, de suerte que al abandonar uno recoge otro y, merced a este trueque, la cantidad total permanece". Por esa razón, abogaba por el secreto, al que consideraba un cimiento de la sociabilidad, una "gran conquista de la Humanidad". De él vale retener la noción de que el secreto no desaparece, solo cambia de sitio. Wikileaks difunde los cables y al punto surge el secreto de Wikileaks (¿Cuáles son sus motivos reales? ¿Qué esconde Julian Assange?).

Desde una perspectiva semiótica, Paolo FABBRI (1998) argumenta en sentido parecido: el secreto no desaparecerá mientras haya comunicación persuasiva; y eso difícilmente ocurrirá pues prácticamente toda comunicación humana lo es. Contra HABERMAS y su ideal normativo del "discurso democrático" y transparente, FABBRI plantea que la comunicación es un quehacer estratégico cuyas armas son, entre otras, el engaño, el fingimiento y la ocultación de información, intenciones y emociones. El secreto es un instrumento del cual nadie que pretenda persuadir se dará el lujo de prescindir. Dice FABBRI: "Se nos insiste que todo, absolutamente todo, está claro, cuando hay secretos que ocupan un lugar central y la realidad circula a su alrededor. La cuestión pasa por saber cómo se interdefinen esos secretos, cómo se interdefinen el secreto y la mentira, pues la mentira parece lo que no es y el secreto es lo que no parece. Esto nos lleva al problema de la naturaleza del lenguaje. Al postulado de que el lenguaje se compone de signos explícitos yo le opondría la idea de que sus componentes contienen secretos. El lenguaje es una conversación colmada de secretos que se intercambian. Todavía no se ha trabajado adecuadamente el funcionamiento de la verdad y la mentira en la sociedad... No hay trasparencia ni puede haberla" (citado en FRANCESCUTTI, 2007: 31).

${ }^{7}$ La mitología "informacionalista" forma parte de la nebulosa utópica que envuelve a la Sociedad de la Información, indica BRETON (1997: 95 y ss.). Recibe su formulación primera en la obra de Norbert WIENER (1950), a la salida de la Segunda Guerra Mundial. BRETON ve en ella una respuesta al horror bélico, y en particular al secreto absoluto del genocidio nazi. En plena crisis de valores tradicionales, se postula la comunicación como un nuevo valor pragmático (¡Comunicaros!) y formal: no importa el contenido de la comunicación, lo fundamental es que tenga lugar (estar conectado). Lo mismo se aplica a la información. 
La imposibilidad de abolir el secreto cuenta a su favor con un argumento teológico: la transparencia exige observadores capaces de ver gracias a ella, y la transparencia total requeriría un observador total; tal sujeto omnividente tiene un nombre conocido: Dios. Únicamente la divinidad podría escrutar todos y cada uno de los vericuetos del entramado social, algo inaccesible a los mortales. La imposibilidad de una observación total la prueba la videovigilancia: no hay operadores suficientes en el mundo para ver todo lo que registran las cámaras: sólo se visionan las grabaciones de aparatos ubicados donde se cree que pasó algo importante; el resto "observa" y registra para nadie.

Por añadidura, cabe dudar de que el desvelamiento de un secreto tenga siempre consecuencias trascendentes. Puede suceder que la gente no quiera escuchar o se niegue a saber (un caso elocuente: las denuncias sobre catástrofes nucleares en la URSS ventiladas a finales de los años ' 50 por refugiados soviéticos nunca fueron tomadas en serio en Occidente porque la mentalidad pronuclear de la época no quería aceptar que tales desastres pudieran ocurrir); o que la revelación no haga mella en sus creencias (véase el nulo impacto de muchas informaciones sobre corrupción en el éxito electoral de los candidatos imputados). Semejante ignorancia en cuanto a la recepción del secreto es inherente a la mitología "informacionalista", que por centrarse en el emisor (periodista, whistleblower, hacker...) y en el mensaje (oculto), olvida al receptor.

Si la transparencia es en definitiva un constructo, habría que preguntarse por el significado actual de su centralidad. Para Rosanvallon (2006: 262) se trata de un corpus ideológico de nuevo cuño: "una verdadera ideología de la transparencia se ha erigido poco a poco en lugar del ideal democrático de producción de un mundo común. La transparencia ha devenido la virtud que ha sustituido a la verdad o a la idea de interés general en un mundo marcado por la incertidumbre". Una ideología de ese tipo resultaría funcional a los ambivalentes discursos sobre la Sociedad de la Información, en los que los ramalazos libertarios se ven teñidos por las sombras de la sospecha (la creencia en que maquinaciones oscuras amenazan a los valores liberales). Pero su índole mistificante no quita que, en determinadas situaciones, pueda sancionar y movilizar demandas aperturistas que acaben desnudando ciertos mecanismos del poder con efectos impredecibles y desestabilizadores. Eso es lo que veremos a continuación.

\section{Conclusiones. Por una transparencia razonable}

El ansia de transparencia no se debilita; más bien ocurre lo contrario. El fenómeno Wikileaks le ha dado nuevas alas, a juzgar por la sucesión de portales creados por algunos medios para recibir "filtraciones", incluso anónimas. La industria de la revelación de secretos crece incontenible. Se expande la prensa del corazón, especializada en parasitar la privacidad de los famosos; y el backstage de los más variados menesteres queda a la vista de todos gracias a portales como YouTube, que, alimentados por aficionados, abren campos de visión al margen de los encuadres mediáticos. Los propios medios se ven empujados a incluir el ideal de transparencia en su ética profesional y a demostrarlo en la práctica (The New York Times desvelando los engaños de uno de sus redactores, Jayson Blair; la cadena árabe Al-Jazeera incluyendo el deber de transparencia en su código deontológico...). En paralelo, se ven sometidos a un escrutinio 
cada vez más intenso desde la blogosfera, en donde se enjuician sus procedimientos y se ventilan sus errores y compromisos.

¿Y qué decir de las consecuencias en el largo plazo? Quizás sea prematuro calibrar el impacto de Wikileaks. Cierto, sus filtraciones pusieron en aprietos al Departamento de Estado estadounidense y dejaron en evidencia a unos cuantos gobiernos, aumentando el malestar popular existente contra ellos (las componendas del gobierno español con la embajada estadounidenses en relación al caso Couso y a la persecución de las descargas de música y películas; el escandaloso tren de vida del ex gobernante tunecino Ben Ali, etcétera). También es perceptible, como apunta ZıZEK (2011), "la apropiación liberal de Wikileaks como otro capítulo en la gloriosa historia de la lucha por el 'flujo libre de información' y del 'derecho de los ciudadanos a saber'. Esta resignificación reduce Wikileaks a un caso extremo de periodismo de investigación" y, por lo tanto, podría redundar en beneficio de las mitologías del Cuarto Poder, la Sociedad de la Información y la Aldea Globa. Sin embargo, ZizeK detecta en sus actividades algo que desborda el marco liberal y que no tiene tanto que ver con el contenido de sus filtraciones como con el funcionamiento habitual del poder. "El objetivo de las revelaciones de Wikileaks no era tanto el de avergonzar a aquellos en el poder sino llevarnos a movilizarnos para implantar un funcionamiento distinto del poder que podría ir más allá de los límites de la democracia representativa" (ZIZEK, 2011). Pero no puede descartarse que la desagradable realidad expuesta, en lugar de movilizar, acreciente el pesimismo y nutra el pensamiento conspirativo, un modo de percibir la realidad que, como señaló el historiador Richard HOFSTADTER (1965), florece entre grupos marginados de un poder al que creen digitado por oscuros demiurgos. "La nueva utopía de la transparencia deviene de tal manera el motor mismo del desencanto que ella pretendía conjurar" (RosANVALLON, 2006).

Habrá que esperar para emitir un juicio fundamentado. Sí parece previsible que, espoleado por Wikileaks, el impulso develador se profundizará; pero una cosa debe quedar clara: que se desvanezcan muchos enigmas no traerá aparejado el fin del secreto. Los "criptoanalistas" (codebreakers) vienen actuando desde la Segunda Guerra Mundial, y no por eso se terminaron las comunicaciones cifradas; simplemente se abrió una carrera sin fín entre creadores de códigos y descifradores, entre hackers y expertos en seguridad informática ${ }^{8}$. Y el secreto diplomático, a pesar de los pesares, no ha muerto; ahora se vehiculizará a través de canales menos vulnerables, como las conversaciones cara a cara. Ni la prensa, por mucha profesión de fe en la transparencia que haga, renunciará a la confidencialidad de sus fuentes, ni al pacto de confianza que fundamenta la interacción off the record; y lo mismo ocurrirá con el secreto profesional en otras áreas. Y no debemos olvidar que la mismísima Red, el ámbito en el que operan los reventadores de secretos, es a la par el reino del anonimato y las identidades falsas.

8 "La utilización de los ordenadores, sin duda, facilita hasta la saturación una exhaustiva información pero también ha enriquecido notablemente las técnicas de codificación y de información destinadas a hacer ininteligibles a intrusos los mensajes reservados" (LOZANO, 1985) 
Ahora bien; el escepticismo sobre la obsesión moderna por la transparencia no lleva necesariamente a abandonar la lucha por una mayor publicidad en los asuntos de interés público. Que la asepsia absoluta sea imposible, no significa que debamos dejar de exigir quirófanos más limpios. Sobran motivos fundamentados para plantear exigencias razonables y puntuales en ese sentido, especialmente en el contexto de sociedades señaladas por burocracias con tradiciones de acendrado hermetismo 9 ; en su consecución la retórica de la transparencia puede brindar una ayuda sumamente eficaz.

Para el enfoque pragmático que defendemos, la cruzada por una mayor visibilidad no debe centrarse exclusivamente en el Estado, dejando en la sombra a los grupos económicos cuyo poder rivaliza con el de éste. Es llamativo que las prometidas revelaciones sobre los desmanes de las grandes corporaciones (una de ellas hecha por el propio Assange a propósito de "un gran banco estadounidense") no se hayan concretado. Pareciera como si la burguesía y sus agentes en los medios pueden admitir que todo sea transparente, todo salvo sus negocios. En esta esfera de la sociedad restan demasiadas incógnitas por desentrañar (el secreto bancario, el entramado de intereses de los medios de comunicación, la financiación oculta de los partidos políticos...); y aunque su exposición parezca un logro modesto en relación a las ambiciones del programa de la transparencia radical, con ella se prestaría un formidable servicio a la causa de la publicidad de los mecanismos de poder en la democracia liberal, además de poner a prueba el compromiso con la transparencia de los mercados tan pregonado por las instituciones económicas. Un servicio formidable que, sin embargo, no debe llevarnos a abrigar ilusiones sobre su efecto en la opinión pública o en la ratio global de secretismo, pues entendemos esos actos develatorios tal como BARTHES entendía el quehacer del mitólogo -otro destructor de opacidades-: una tarea a ejecutar "sin esperanza de retorno, sin presuponer ninguna compensación... (sin) imaginar lo que será sensiblemente el mundo cuando el objetivo inmediato de su crítica haya desaparecido; la utopía, para él, es un lujo imposible; duda mucha de que las verdades de mañana sean el reverso exacto de las mentiras de hoy... no ve la tierra prometida... todos los valores de su empresa se le aparecen como actos de destrucción... Y a pesar de todo, nuestra búsqueda debe estar encaminada a lograr una reconciliación de lo real y los hombres, de la descripción y la explicación, del objeto y del saber" (BARTHES, 1981: 255 y ss.).

9 España es un ejemplo. Figura entre los cinco países de la Unión Europea que no ha regulado el acceso de la ciudadanía a la información en poder de la administración, derecho garantizado por el artículo $105 \mathrm{~B}$ de la Constitución Española. El gobierno socialista prometió regularlo, compromiso que incumplió en la primera legislatura. A finales del año 2009, existía un borrador de anteproyecto, muy difícil de conocer. Finalmente, la ONG Access Info Europe (http://www.access-info.org/es) obtuvo el borrador a través de una filtración. Que la futura ley de Transparencia Ley de Transparencia y Acceso a la Información pública sólo pueda conocerse mediante una filtración dice mucho de las inercias secretistas del Estado español. Por último, el borrador fue archivado y no será tramitado en lo que resta de legislatura. 


\section{Referencias bibliográficas}

ADORNO, Theodor y HORKHEIMER, Max (1969): Dialéctica del Iluminismo. Buenos Aires, Sur.

BARTHES, Roland (1981): Mitologías. México, Siglo XXI.

BAUME, Sandrine. (2011): "Transparency in the Handling of public Affairs", ponencia presentada en la $1^{\text {st }}$ Global Conference on Transparency Research, Rutgers University, http://spaa.newark.rutgers.edu/images/stories/documents/Transparency_Research_Conference/Papers/Baume_Sandrine.pdf [fecha de consulta: 13 de junio de 2011]

BERTONI, Eduardo (2011): "Freedom of Information. Three harmless words? The role of the media and access to information laws", ponencia presentada en la $1^{\text {st }}$ Global Conference on Transparency Research, Rutgers University (Newark), http://spaa.newark.rutgers.edu/images/stories/documents/Transparency_Research Conference/Papers/Bertoni_Eduardo.pdf [fecha de consulta: 13 de junio de 2011]

BRETON, Philippe (1997): L'utopie de la communication, Le mythe du «village planetaire». Paris, Ed. La Découverte

FABBRI, Paolo (1998): "El tema del secreto", en Tácticas de los signos. Barcelona, Gedisa.

FENSTER, Mark (1999): Conspiracy Theories: secret and Power in American Culture. Minneapolis, University of Minnesotta Press.

FOUCAULT, Michel (2004): Vigilar y castigar. Buenos Aires, Ed. Siglo XXI.

FREUND, Gisèle (1993): La fotografía como documento social. Barcelona, Gustavo Gili Editor.

FRANCESCUTTI, Pablo (2007): "El rostro oscuro de la comunicación", en Punto de Vista. Buenos Aires, $\mathrm{n}^{\circ}$ 86, 31-36 pp.

GALLAGHER, Ailleen (2006): The Muckrakers, American Journalism During the Age of Reform. New York, The Rosen Publishing Group.

HABERMAS, Jürgen (2009):Historia y crítica de la opinión pública. La transformación estructural de la vida pública. Barcelona, Gustavo Gili.

HOFSTADTER, Richard (1965): The Paranoid Style in American Politics, and Other Essays. New York, Knopf.

JOHNSON, Roberta Ann (2002): Whistleblowing: When It Works-and Why. Boulder (Colorado), Rienner Publishers.

LEMOV, Michael (2011): People's Warrior: John Moss and the Fight for Freedom of Information and Consumer Rights. New Jersey, Fairleigh Dickinson University Press.

LOZANO, Jorge (1985): "El secreto en la sociedad de la información”, El País, Madrid, 16 de noviembre. Sección Opinión, página 15.

MEYROVITZ, Joshua (1985): No Sense of Place: The Impact of Electronic on Social Behaviour. Oxford, Oxford University Press. 
ROSANVALLON, Pierre (2006): La contre-démocratie. La politique à l'âge de la défiance. Paris, Seuil.

SIMMEL, Georg (1906): "The Sociology of Secrecy and of Secret Societies", American Journal of Sociology $\mathrm{n}^{\mathrm{0}}$ 11. Chicago, University of Chicago Press, pp. 441498.

SONTAG, Susan (1996): Sobre la fotografía. Barcelona, Edhasa.

THOMPSON, John B. (1997): Los medios y la modernidad. Barcelona, Paidós.

WIENER, Norbert (1950): The Human Use of Human Beings: Cybernetics and Society. Houghton Mifflin Co, The Riverside Press.

WOODWARD, Bob (1988): Veil: Las Guerras secretas de la CIA. Barcelona, Ediciones $\mathrm{B}$.

ZIZEK, Slavoj (2011): "Good Manners in the Age of Wikileaks". London Review of Books, Londres, Nicholas Spice Pub., Vol. 33 n 2, pp 9-10. 